\title{
Socio-economic and demographic characteristics associated with risk behaviour patterns for chronic non-communicable diseases in Brazil: data from the National Health Survey, 2013
}

\author{
Ana Paula P Duarte ${ }^{1}$, Paulo Rogério Melo Rodrigues ${ }^{1}$, Márcia Gonçalves Ferreira $^{1}$, \\ Diana Barbosa Cunha ${ }^{2}$, Naiara Ferraz Moreira ${ }^{3}$, Rosely Sichieri ${ }^{4}$ and Ana Paula Muraro ${ }^{5, *}$ \\ 'Department of Food and Nutrition, Federal University of Mato Grosso, Cuiabá, MG, Brazil: ${ }^{2}$ Department of Social \\ Medicine, State University of Rio de Janeiro, Rio de Janeiro, RJ, Brazil: ${ }^{3}$ Faculty of Health Sciences, Federal University \\ of Grande Dourados, Dourados, MS, Brazil: ${ }^{4}$ Department of Epidemiology, Institute of Social Medicine, Rio de \\ Janeiro State University, Rio de Janeiro, RJ, Brazil: ${ }^{5}$ Institut of Public Health, Department of Public Health, Federal \\ University of Mato Grosso, Av. Fernando Corrêa da Costa 2367, Bairro Boa Esperança, Bloco: CCBS III, Cuiabá, \\ MT 78060-900, Brazil
}

Submitted 11 June 2018: Final revision received 19 November 2018: Accepted 16 January 2019: First published online 12 March 2019

\begin{abstract}
Objective: To identify risk behaviour patterns for chronic non-communicable diseases (NCD) in the Brazilian population and to investigate associated socioeconomic and demographic factors.

Design: Factor analysis was used to identify patterns considering the following risk behaviours: consumption of soft drinks/artificial juice, sweet foods, red meat with apparent fat, chicken skin; inadequate consumption of fruits and vegetables; alcohol abuse; smoking; absence of physical activity during leisure time; and time spent watching television. The $\chi^{2}$ test was used to compare ratios. All analyses accounted for weighting factors and the study's complex sampling design effect. The socio-economic and demographic variables evaluated were gender, age, schooling level and macro region of residence.

Setting: National Health Survey, a household survey with national representation, conducted in 2013 in Brazil.

Participants: Individuals ( $n 60202$ ) aged 18 years or over.

Results: Four risk behaviour patterns were identified: 'Physical inactivity in leisure time and Inadequate consumption of fruits and vegetables', 'Saturated fat', 'Alcohol and Smoking' and 'Sedentary behaviour and Sugar', explaining 52.01 \% of the total variance. Overall, greater adherence to 'Saturated fat' and 'Alcohol and Smoking' patterns was observed among men and those with lower education level. The 'Sedentary behaviour and Sugar' and 'Physical inactivity in leisure time and Inadequate consumption of fruits and vegetables' patterns had greater adherence among younger individuals, and the first was associated with higher education whereas the second with less education among individuals residing in the North and Northeast regions.

Conclusions: Risk behaviour patterns for NCD were heterogeneous, reflecting the socio-economic and demographic differences in Brazil.
\end{abstract}

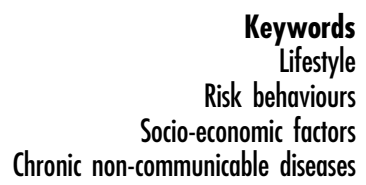

Chronic non-communicable diseases (NCD) account for approximately $60 \%$ of all causes of death worldwide. It is estimated that $80 \%$ of these deaths occur in low- and middle-income countries ${ }^{(1)}$. Among the major modifiable risk factors associated with these diseases are lifestylerelated behaviours such as smoking, physical inactivity, alcohol abuse and insufficient consumption of fruits and vegetables $^{(2,3)}$.
In this context, knowing the occurrence of each risk behaviour provides a partial view of the problem, since these are highly interrelated ${ }^{(4)}$ and may present synergistic effects, potentiating the risk when occurring in an aggregate form $^{(5)}$, which makes relevant the knowledge about aggregation of such behaviours that are influenced by sociodemographic and economic factors as gender, age and socio-economic status ${ }^{(6)}$. Studies with different 
population groups have evaluated the simultaneity or cooccurrence of risk behaviours and their association with $\mathrm{NCD}^{(7-11)}$. However, most of them evaluated the cooccurrence of behaviours without considering the interrelationships between them ${ }^{(12)}$.

In Brazil, some studies also investigated the simultaneity of risk behaviours for NCD in adults ${ }^{(13-18)}$. However, only two studies found in the literature have identified risk behaviour patterns in a Brazilian national sample ${ }^{(9,19)}$. The first interviewed adults in a survey via telephone (VIGITEL) conducted annually in Brazilian capitals and in the Federal District; and the second with adolescents, based on data from the National School Health Survey (PeNSE), was conducted in 2012 with students from the 9th year of primary education in public and private schools. Therefore, none of the studies evaluated a probabilistic sample in the entire national territory of Brazil.

Thus, the present study aimed to identify risk behaviour patterns for NCD in the Brazilian population and associated socio-economic and demographic factors, using data from the most complete survey on the health of the Brazilian population, the National Health Survey (PNS).

\section{Methods}

The present study uses data from the PNS, a Brazilian home-based survey conducted in 2013 by the Brazilian Institute of Geography and Statistics in partnership with the Health Surveillance Secretariat of the Ministry of Health and the Oswaldo Cruz Foundation.

The sample plan was defined by probabilistic sampling in three stages. In the first stage, there was a stratification of primary sampling units, constituted by sectors or groups of census sectors, the second stage consisted of homes, and residents aged 18 years or over corresponded to the third stage units. The selection of a sub-sample of the primary sampling units was made by simple random sampling ${ }^{(20)}$.

The estimated sample size was based on 81357 homes and interview records were obtained in 64348 of them, and 60202 individuals aged 18 years or older were interviewed. Considering closed homes, the loss ratio was $20.8 \%$ and the non-response ratio was $8 \cdot 1 \%$. Details on the PNS methodological strategy design and the sampling process are available in other publications ${ }^{(21,22)}$.

Participants were interviewed and answered questions related to socio-economic, demographic and lifestyle information. The socio-economic and demographic variables evaluated in the present study were: gender (male/ female); age categorized in age groups (18-24, 25-39, 40-59, 50-59 and $\geq 60$ years); schooling level (none/ incomplete primary education; complete primary education/incomplete secondary education; complete secondary education/incomplete higher education; complete higher education) and macro region of residence (CentralWest, South, Southeast, North, Northeast).

Regarding food consumption information, the weekly intake frequency of soft drinks/artificial juice and sweet foods was obtained by a questionnaire, asking the following questions: 'How many days in the week you usually drink artificial juice?' and How many days in the week you usually eat sweet foods?'. Questionnaire answer was the number of days in the week. For fruits and vegetables, the number of days in the week was obtained by the questions: 'How many days of the week do you usually eat lettuce and tomato salad or salad from any other raw vegetables or vegetables?', 'How many days of the week do you usually eat vegetables or boiled vegetables such as cabbage, carrots, chuchu, eggplant, zucchini? (not counting potatoes, manioc or yams)' and 'How many days in the week do you usually eat fruit?'.

For descriptive analyses, the lifestyle behaviours analysed were categorized as follows: (i) consumption of soft drinks/artificial juice (5 times/week or more); (ii) consumption of sweet foods ( 5 times/week or more); (iii) inadequate consumption of fruits, (iv) green or raw vegetable salad, (v) cooked vegetables (4 times/week or less for fruits and vegetables); (vi) consumption of red meat with apparent fat (yes or no); (vii) chicken skin consumption (yes or no); (viii) excessive consumption of alcoholic beverages (for men 5 doses or more and for women 4 doses or more of alcoholic beverages on a single occasion in the $30 \mathrm{~d}$ prior to the interview); (ix) daily or sporadic use of tobacco; (x) absence of physical activity in leisure; and (xi) time spent watching television $(3 \mathrm{~h} / \mathrm{d}$ or more) to characterize sedentary behaviour.

For the identification of risk behaviour patterns (dependent variable), we used exploratory factor analysis to reduce the initial number of variables into a smaller set of factors that represent, in a synthetic way, the information contained in the larger set of variables ${ }^{(23)}$. The following behaviour factors were included in the model: (i) consumption of soft drinks/artificial juice (0 to 7 times/ week); (ii) consumption of sweet foods (0 to 7 times/ week); (iii) inadequate consumption of fruits, (vi) green or raw vegetable salad, (v) cooked vegetables (0 to 7 times/ week); (vi) consumption of red meat with apparent fat; (vii) chicken skin consumption; (viii) excessive consumption of alcoholic beverages; (ix) daily or sporadic use of tobacco; (x) physical activity in leisure (0 to 7 times/ week); and (xi) time spent watching television (categorical, from $1=$ 'do not watch television or watch for less than $1 \mathrm{~h} / \mathrm{d}$ ' to $7=$ watch television for $6 \mathrm{~h} / \mathrm{d}$ or more') to characterize sedentary behaviour.

Data adequacy for the factor analysis was initially evaluated using the Bartlett sphericity test and the KaiserMeyer-Olkin sample adequacy measure ${ }^{(24)}$. Analysis of main components was used for factor extraction and varimax rotation was conducted to facilitate the 
interpretation of factors. Determination of the number of factors to retain was based on the Kaiser criterion, which proposes the retention of factors with eigenvalues $\geq 1^{(25)}$.

Standardized factor scores ( $Z$-scores) were assigned to each participant, for each of the retained patterns, calculated based on factor loading. The higher the $Z$-score value, the greater the participant's adherence to that pattern $^{(26)}$. Behaviours with a factor loading $|\geq 0 \cdot 30|$ remained in the patterns, with higher values indicating greater contribution of the behaviour to the specific pattern construction. Afterwards, identification of behaviour patterns stratified by the presence or absence of NCD (systemic arterial hypertension, diabetes, increased cholesterol and/ or obesity) was carried out.

Blood pressure was measured using an automatic device following the same procedures used in the Longitudinal Study of Adult Health (ELSA) Project ${ }^{(21)}$ and participants were classified as hypertensive if they had systolic blood pressure $\geq 140 \mathrm{mmHg}$ and/or diastolic blood pressure $\geq 90 \mathrm{mmHg}^{(27)}$. Participants who reported a medical diagnosis of systemic arterial hypertension and were taking antihypertension medication were also considered hypertensive.

To evaluate obesity, participants' weight was obtained by means of a digital scale and height was measured by a portable stadiometer, for subsequent calculation of BMI. Weight was measured using a portable digital scale with capacity of $150 \mathrm{~kg}$ and gradation of $100 \mathrm{~g}$. Before weighing, the scale was placed on a flat surface and properly calibrated. In addition, participants were asked to remove their shoes, heavy clothing and accessories. The weight was recorded in kilograms considering the first decimal place shown by the scale display. Height was measured by a portable stadiometer with a retractable treadmill, measuring to the nearest $0 \cdot 1 \mathrm{~cm}$. Participants were instructed to adopt the orthostatic position, parallel feet and barefoot; before measurement, the examiner ensured that five points (heels, calves, buttocks, scapulae and the back of the occiput) were against the wall. The height record was in centimetres considering the first decimal place ${ }^{(28)}$. In the identification of obesity, the cut-off point was $\mathrm{BMI} \geq 30 \cdot 0 \mathrm{~kg} / \mathrm{m}^{2}$. Information on diabetes and increased cholesterol was based on self-report according to previous medical diagnosis.

Statistical analyses were performed with the statistical software package SPSS Statistics version 17.0 and using the Complex Sample module, considering the study design and sample weights. The $\chi^{2}$ test was used to compare the prevalence of behaviour patterns according to independent variables. Factor scores of retained patterns were categorized into tertiles.

The PNS was approved by the National Commission of Ethics for Research in Human Beings, of the Ministry of Health, under the opinion number 328,159 of 26 June 2013. Individuals invited and who accepted to participate in the research signed an Informed Consent Form.

\section{Results}

A total of 60202 Brazilians aged 18 years or over were analysed, of whom $52.9 \%$ were female, $66.0 \%$ were aged between 25 and 59 years and $54.5 \%$ had low educational level (without education or incomplete secondary education). Regarding the risk behaviours evaluated, the highest prevalence was observed for physical inactivity at leisure time $(68.5 \%)$ followed by inadequate consumption of cooked vegetables $(68.0 \%)$, inadequate consumption of fruits $(58.6 \%)$, inadequate consumption of green or raw vegetable salad (53.5\%), and sedentary behaviour and consumption of meat with apparent fat, both with $28.9 \%$ each (Table 1).

In the stratified analysis, no relevant differences were observed either in the identification of patterns or in the parameters evaluated between the population with and without self-report of some NCD (see online supplementary material, Supplemental Tables 1 and 2). Thus, the identification of patterns and conduction of analyses were done for the entire sample population.

The Kaiser-Meyer-Olkin measure $(=0.64)$ and Bartlett's sphericity test $(P<0 \cdot 01)$ indicated that the correlations between behaviours were sufficient and adequate for conducting the factor analysis. The identified patterns were named as follows: (i) 'Physical inactivity in leisure time and Inadequate consumption of fruits and vegetables' pattern, characterized by the absence of physical activity in leisure time and consumption below recommended levels for fruits and vegetables, explaining $18.43 \%$ of the variance; (ii) 'Saturated fat' pattern, characterized by the consumption of chicken with skin and red meat with apparent fat, explaining $13.42 \%$ of data variation; (iii) 'Alcohol and Smoking' pattern, with positive loadings for excessive consumption of alcoholic beverages and smoking, with a 10.41\% explanation of variance; and (iv) 'Sedentary behaviour and Sugar' pattern, characterized by $\geq 3 \mathrm{~h} / \mathrm{d}$ spent watching television, regular consumption of sweet foods and soft drinks/artificial juices, which explained $9.75 \%$ of the variance. Together, the four risk behaviours explained $52.01 \%$ of behaviour variability (Table 2).

It was observed that the pattern 'Physical inactivity in leisure time and Inadequate consumption of fruits and vegetables' showed a higher adherence among men, those who were younger, in the population with the lowest level of schooling, and those who resided in the North and Northeast regions. The 'Saturated fat' pattern was more frequent among men, in the population with lower educational level and residents in the South and Central-West regions of the country. For the 'Alcohol and Smoking' pattern, the highest adherence was also among men, people with lower educational levels, and residents in the Central-West and Northeast regions. In contrast, the 'Sedentary behaviour and Sugar' pattern had greater adherence among the younger participants (18-24 years old), with higher level of schooling, and residents in the South and Southern regions (Table 3). 
Table 1 Distribution of the study population according to socio-economic and demographic characteristics, economic and risk behaviour characteristics for chronic non-communicable diseases. National Health Survey, Brazil, 2013 ( $n 60$ 202)

\begin{tabular}{|c|c|c|c|}
\hline & $n$ & $\%$ & $95 \% \mathrm{Cl}$ \\
\hline \multicolumn{4}{|l|}{ Gender } \\
\hline Male & 25920 & $47 \cdot 1$ & $46 \cdot 4,47 \cdot 8$ \\
\hline Female & 34282 & $52 \cdot 9$ & $52 \cdot 2,53 \cdot 6$ \\
\hline \multicolumn{4}{|l|}{ Age (years) } \\
\hline $18-24$ & 7823 & $15 \cdot 9$ & $15 \cdot 4,16 \cdot 5$ \\
\hline 25-39 & 20767 & $31 \cdot 8$ & $31 \cdot 1,32 \cdot 4$ \\
\hline $40-59$ & 20435 & 34.2 & $33.6,34.9$ \\
\hline$\geq 60$ & 11177 & $18 \cdot 1$ & $17.5,18.6$ \\
\hline \multicolumn{4}{|l|}{ Schooling } \\
\hline None/incomplete primary education & 24083 & 38.9 & $38.3,39.6$ \\
\hline Complete primary education/incomplete secondary education & 9215 & $15 \cdot 6$ & $15 \cdot 0,16 \cdot 0$ \\
\hline Complete secondary education/incomplete higher education & 19149 & $32 \cdot 8$ & $32 \cdot 1,33 \cdot 5$ \\
\hline Complete higher education & 7755 & $12 \cdot 7$ & $12 \cdot 3,13 \cdot 2$ \\
\hline \multicolumn{4}{|l|}{ Region } \\
\hline North & 12536 & 7.4 & $7 \cdot 2,7 \cdot 7$ \\
\hline Northeast & 18305 & $26 \cdot 6$ & $26 \cdot 0,27 \cdot 2$ \\
\hline Southeast & 14294 & 43.8 & $43 \cdot 1,44.5$ \\
\hline South & 7548 & $14 \cdot 8$ & $14 \cdot 3,15 \cdot 3$ \\
\hline Central-West & 7519 & 7.4 & $7 \cdot 1,7 \cdot 6$ \\
\hline \multicolumn{4}{|l|}{ Risk behaviours } \\
\hline Absence of physical activity in leisure time & 42306 & 68.5 & $67 \cdot 8,69 \cdot 1$ \\
\hline Irregular intake of green or raw vegetable salad* & 34615 & 53.5 & $52 \cdot 7,54 \cdot 2$ \\
\hline Irregular intake of cooked vegetables ${ }^{*}$ & 41744 & 68.0 & $67 \cdot 3,68.7$ \\
\hline Irregular intake of fruits* & 35797 & $58 \cdot 6$ & $57 \cdot 9,59 \cdot 3$ \\
\hline Intake of meat with apparent fat & 16211 & 28.9 & $28 \cdot 2,29.5$ \\
\hline Intake of chicken with skin & 11852 & $22 \cdot 3$ & $21 \cdot 7,22 \cdot 9$ \\
\hline Sedentary behaviourt & 17769 & $28 \cdot 9$ & $28 \cdot 2,29 \cdot 6$ \\
\hline Smokingł & 8729 & 14.5 & $14 \cdot 2,15 \cdot 2$ \\
\hline Alcohol abuse§ & 8104 & 13.7 & $13 \cdot 2,14 \cdot 2$ \\
\hline Intake of soft drinks/artificial juices\| & 13088 & $23 \cdot 4$ & $22 \cdot 7,24 \cdot 0$ \\
\hline Regular intake of sweet foods $\|$ & 11262 & $21 \cdot 7$ & $21 \cdot 1,22 \cdot 3$ \\
\hline
\end{tabular}

${ }^{*}$ Frequency of consumption: 4 times/week or less.

†Time spent watching television: $3 \mathrm{~h} / \mathrm{d}$ or more.

‡Daily or sporadic tobacco use.

$\S$ Intake of alcoholic beverages on a single occasion in the last $30 \mathrm{~d}$ : intake of 5 doses or more for men and 4 doses or more for women.

$\|$ Frequency of consumption: 5 times/week or more.

\section{Discussion}

Four risk behaviour patterns for NCD were identified in the Brazilian population, denominated 'Physical inactivity in leisure time and Inadequate consumption of fruits and vegetables', 'Saturated fat', 'Alcohol and Smoking' and 'Sedentary behaviour and Sugar'. These patterns showed heterogeneity regarding the socio-economic and demographic characteristics of the population, also varying according to regions of the country. Moreover, in general, our study revealed a trend of greater adherence to risk behaviours among men, younger individuals and those with lower schooling levels.

The risk behaviours analysed in the present study are characteristics of an unhealthy lifestyle and are known risk factors for the main NCD, responsible for a large share of the global burden of diseases ${ }^{(2,3)}$. The diversity of factors considered in studies evaluating the co-occurrence of risk behaviours for NCD and the criteria used in the classification of such factors make the comparison of results complex, and it should be noted that the patterns identified in the present study differ partially from those observed in other countries and even in Brazil ${ }^{(7-11)}$, except for the pattern that associates smoking with the consumption of alcoholic beverages, which has been identified in several studies ${ }^{(29-31)}$. In a study with data from the PNS of 2013, Garcia and Freitas ${ }^{(29)}$ observed a higher prevalence of alcohol abuse among occasional smokers (35.2\%) compared with daily smokers (27.4\%), and such categories had higher prevalence of alcohol abuse than among non-smokers (11.1\%).

In Brazil, among the nationally representative studies that used statistical procedures to identify behaviour patterns, Steele et al. ${ }^{(9)}$ verified the presence of two patterns from a list of twelve risk behaviours, with gender-stratified analysis. One pattern was characterized by healthy behaviours, called prudent, and the other one was represented by unhealthy behaviours, both with similar characteristics between men and women. Greater adherence to the prudent pattern was observed among women, from less developed regions (North and Northeast), with higher age groups and higher schooling level. On the other hand, the 
Table 2 Factor loads, commonalities $\left(h_{2}\right)$ and estimated variances for the four patterns of risk behaviours for chronic non-communicable diseases identified among Brazilians. National Health Survey, Brazil, 2013 ( $n 60$ 202)

\begin{tabular}{|c|c|c|c|c|c|}
\hline & \multicolumn{4}{|c|}{ Factor loading } & \multirow[b]{2}{*}{$h_{2}$} \\
\hline & $\begin{array}{l}\text { Physical inactivity } \\
\text { in leisure time } \\
\text { and Inadequate } \\
\text { consumption of FV }\end{array}$ & Saturated fat & Alcohol and Smoking & $\begin{array}{c}\text { Sedentary behaviour } \\
\text { and Sugar }\end{array}$ & \\
\hline Absence of physical activity in leisure time & 0.395 & 0.078 & -0.032 & -0.027 & 0.164 \\
\hline Irregular intake of green or raw vegetable salad & 0.797 & -0.077 & -0.002 & 0.032 & 0.642 \\
\hline Irregular intake of cooked vegetables & 0.757 & -0.007 & -0.011 & 0.054 & 0.576 \\
\hline Irregular intake of fruits & 0.636 & 0.155 & 0.171 & -0.011 & 0.459 \\
\hline Intake of meat with apparent fat & 0.110 & 0.753 & 0.175 & 0.135 & 0.626 \\
\hline Intake of chicken with skin & 0.051 & 0.810 & 0.039 & 0.027 & 0.661 \\
\hline Smoking & 0.090 & 0.095 & 0.703 & -0.106 & 0.523 \\
\hline Alcohol abuse & -0.052 & 0.107 & 0.724 & 0.110 & 0.550 \\
\hline Sedentary behaviour & 0.026 & -0.284 & 0.336 & 0.428 & 0.377 \\
\hline Intake of soft drinks/artificial juices & 0.140 & 0.151 & 0.121 & 0.691 & 0.535 \\
\hline Regular intake of sweet foods & -0.144 & 0.093 & -0.212 & 0.731 & 0.609 \\
\hline Eigenvalue & 2.03 & 1.48 & 1.15 & 1.07 & \\
\hline$\%$ variance explained & $18 \cdot 43$ & 13.42 & $10 \cdot 41$ & 9.75 & \\
\hline$\%$ cumulative variance explained & 18.43 & 31.85 & $42 \cdot 26$ & $52 \cdot 01$ & \\
\hline
\end{tabular}

FV, fruits and vegetables.

Factors loading on each pattern are indicated in bold.

male population from more developed regions (South, Southeast and Central-West), those younger and with lower schooling level showed greater adherence to the second pattern. However, the authors emphasize as a limitation of the study the fact of reflecting only the reality of Brazilian capitals and the Federal District and not the entire national territory.

Since there are sociodemographic and economic differences in Brazil, it is important to consider that the level of poverty can affect behaviours related to health promotion and maintenance. Low purchasing power and low schooling level are clearly related to poorer health conditions ${ }^{(3)}$. The influence of schooling on risk behaviours reinforces the hypothesis of social determination of these behaviours.

Risk behaviour patterns reflect the inequalities and vulnerability of some social segments. These inequalities were well described in the study of Barros et al. ${ }^{(18)}$ with data from the PNS 2013, which detected differences in the prevalence of health risk behaviours (smoking, alcohol abuse, sedentary behaviour, below-recommended consumption of fruits and vegetables, among others) by gender and schooling level. The results of the present study reinforce the need to consider those differences in the development of public policies aiming at the promotion of healthy behaviours.

In the present study, 'Physical inactivity in leisure time and Inadequate consumption of fruits and vegetables' was the main pattern, explaining $18.43 \%$ of the variance. A similar pattern was verified by Camões and Lopes $^{(32)}$ in Portuguese adults, who found an association between higher level of physical activity and consumption of a healthy diet. Also, in their study with French women,
Estaquio et al. ${ }^{(33)}$ observed that the most active were those with higher consumption of fruits, vegetables and greens.

When assessing the low adherence to fruit and vegetable consumption, mainly in low economic groups ${ }^{(34)}$, access to these foods should be considered, mainly determined by the population's purchasing power, given that greater monetary expenditure on food is associated with consumption of healthier foods, more specifically greater intake of fruits and vegetables ${ }^{(35)}$. This fact may explain, at least in part, the greater adherence to the 'Physical inactivity in leisure time and Inadequate consumption of fruits and vegetables' pattern verified in the present study for the population with lower schooling level and residing in less developed regions of the country (North and Northeast). Another possible explanation may be the issue of urban violence, since it inhibits the population to practise outdoor physical activities in leisure time, especially women. The North and Northeast regions include coincidentally the six states with the highest homicide rate in the country ${ }^{(36)}$.

In the present study, the 'Saturated fat' pattern, which explained $13.42 \%$ of the variance, may be reflecting cultural aspects as well as greater access to sources of high-fat foods. Meat consumption contributes to the excessive intake of saturated fat, this habit being spread throughout the national territory and incorporated more strongly in the gastronomic culture of some regions, considering that Brazil is among the great powers in beef and chicken production ${ }^{(37)}$. In 2015, among the twenty municipalities with the largest beef production, thirteen were in the Central-West region, five in the North region and two in the South region ${ }^{(38)}$, a fact that may justify the greater adherence to the 'Saturated fat' pattern in Central-West 


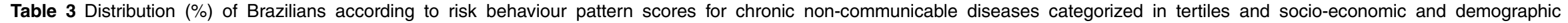
characteristics. National Health Survey, Brazil, 2013 ( $n 60$ 202)

\begin{tabular}{|c|c|c|c|c|c|c|c|c|c|c|c|c|c|c|c|c|}
\hline & \multicolumn{4}{|c|}{$\begin{array}{l}\text { Physical inactivity in leisure time and } \\
\text { Inadequate consumption of FV }\end{array}$} & \multicolumn{4}{|c|}{ Saturated fat } & \multicolumn{4}{|c|}{ Alcohol and Smoking } & \multicolumn{4}{|c|}{ Sedentary behaviour and Sugar } \\
\hline & $\begin{array}{c}\mathrm{T} 1 \\
(\leq-0.467)^{*}\end{array}$ & $\begin{array}{c}\mathrm{T} 2 \\
(-0.468 \\
\text { to } 0.513)\end{array}$ & $\begin{array}{c}\text { T3 } \\
(\geq 0.514)\end{array}$ & $\begin{array}{c}P \\
\text { value† }\end{array}$ & $\begin{array}{c}\mathrm{T} 1 \\
(\leq-0.564)\end{array}$ & $\begin{array}{c}\mathrm{T} 2 \\
(-0.565 \\
\text { to } 0.031)\end{array}$ & $\begin{array}{c}\text { T3 } \\
(\geq 0.032)\end{array}$ & $\begin{array}{c}P \\
\text { value }\end{array}$ & $\begin{array}{c}\mathrm{T} 1 \\
(\leq-0.0551)\end{array}$ & $\begin{array}{c}\mathrm{T} 2 \\
(-0.552 \text { to } \\
-0.063)\end{array}$ & $\begin{array}{c}\text { T3 } \\
(\geq-0.064)\end{array}$ & $\begin{array}{c}P \\
\text { value }\end{array}$ & $\begin{array}{c}\mathrm{T} 1 \\
(\leq-0.568)\end{array}$ & $\begin{array}{c}\mathrm{T} 2 \\
(-0.569 \\
\text { to } 0.369)\end{array}$ & $\begin{array}{c}\text { T3 } \\
(\geq 0.370)\end{array}$ & $\begin{array}{c}P \\
\text { value }\end{array}$ \\
\hline Gender & & & & $<0.01$ & & & & $<0.01$ & & & & $<0.01$ & & & & $<0.01$ \\
\hline Male & 31.5 & 34.2 & 34.3 & & 24.7 & 29.5 & 45.9 & & 32.4 & $27 \cdot 7$ & 39.9 & & 30.4 & 32.6 & 37.0 & \\
\hline Female & $40 \cdot 6$ & 33.1 & $26 \cdot 3$ & & 34.9 & $37 \cdot 7$ & $27 \cdot 3$ & & 37.7 & $35 \cdot 2$ & $27 \cdot 1$ & & 31.9 & $32 \cdot 6$ & 35.5 & \\
\hline Age (years) & & & & $<0.01$ & & & & $<0.01$ & & & & $<0.01$ & & & & $<0.01$ \\
\hline $18-24$ & 26.9 & 34.5 & 38.6 & & 31.4 & 30.7 & 37.8 & & 39.4 & 28.4 & $32 \cdot 2$ & & $16 \cdot 0$ & $29 \cdot 3$ & 54.7 & \\
\hline $25-39$ & 33.6 & 34.6 & 31.8 & & $27 \cdot 6$ & 32.4 & $40 \cdot 0$ & & 34.6 & 30.7 & 34.7 & & 24.7 & 34.5 & $40 \cdot 8$ & \\
\hline $40-59$ & 39.6 & 33.1 & $27 \cdot 3$ & & $28 \cdot 3$ & 35.4 & $36 \cdot 3$ & & 33.3 & 31.8 & 34.9 & & 37.7 & 32.8 & 29.5 & \\
\hline$\geq 60$ & 43.2 & $32 \cdot 2$ & 24.6 & & $36 \cdot 6$ & $36 \cdot 1$ & $27 \cdot 2$ & & $36 \cdot 1$ & $36 \cdot 2$ & $27 \cdot 8$ & & $43 \cdot 6$ & $31 \cdot 8$ & $24 \cdot 6$ & \\
\hline Schoooling & & & & $<0.01$ & & & & $<0.01$ & & & & $<0.01$ & & & & $<0.01$ \\
\hline $\begin{array}{l}\text { None/incomplete } \\
\text { primary } \\
\text { education }\end{array}$ & $28 \cdot 4$ & $33 \cdot 3$ & $38 \cdot 3$ & & $29 \cdot 4$ & $31 \cdot 8$ & 38.8 & & $34 \cdot 0$ & $30 \cdot 6$ & $35 \cdot 4$ & & $40 \cdot 3$ & $32 \cdot 1$ & $27 \cdot 6$ & \\
\hline $\begin{array}{l}\text { Complete primary } \\
\text { education/ } \\
\text { incomplete } \\
\text { secondary } \\
\text { education }\end{array}$ & $31 \cdot 8$ & $36 \cdot 4$ & $31 \cdot 8$ & & $30 \cdot 3$ & $29 \cdot 1$ & $40 \cdot 6$ & & $32 \cdot 5$ & $30 \cdot 5$ & $37 \cdot 0$ & & $25 \cdot 9$ & $32 \cdot 3$ & $41 \cdot 7$ & \\
\hline $\begin{array}{l}\text { Complete } \\
\text { secondary } \\
\text { education/ } \\
\text { incomplete } \\
\text { higher } \\
\text { education }\end{array}$ & $39 \cdot 8$ & $34 \cdot 5$ & $25 \cdot 7$ & & $32 \cdot 4$ & $33 \cdot 2$ & $34 \cdot 4$ & & $35 \cdot 3$ & 33.4 & $31 \cdot 3$ & & 23.7 & $33 \cdot 6$ & $42 \cdot 7$ & \\
\hline $\begin{array}{l}\text { Complete higher } \\
\text { education }\end{array}$ & $57 \cdot 1$ & $29 \cdot 0$ & 13.9 & & $26 \cdot 1$ & $47 \cdot 4$ & $26 \cdot 5$ & & $41 \cdot 8$ & $32 \cdot 1$ & $26 \cdot 1$ & & 28.9 & $32 \cdot 0$ & $39 \cdot 1$ & \\
\hline Region & & & & $<0.01$ & & & & $<0.01$ & & & & $<0.01$ & & & & $<0.01$ \\
\hline North & $16 \cdot 6$ & $32 \cdot 4$ & 51.0 & & 38.2 & 29.6 & $32 \cdot 2$ & & 31.2 & 34.5 & 34.3 & & 37.9 & 34.7 & $26 \cdot 4$ & \\
\hline Northeast & $25 \cdot 6$ & $32 \cdot 4$ & $42 \cdot 0$ & & 37.9 & 34.2 & $27 \cdot 9$ & & $35 \cdot 1$ & 30.7 & 34.3 & & $36 \cdot 4$ & 33.6 & $30 \cdot 0$ & \\
\hline Southeast & $42 \cdot 7$ & 34.5 & 22.9 & & $27 \cdot 8$ & 34.0 & 38.2 & & 34.2 & $32 \cdot 7$ & 33.1 & & $28 \cdot 2$ & 31.5 & $40 \cdot 3$ & \\
\hline South & 44.6 & 33.4 & 22.0 & & 22.8 & 34.9 & $42 \cdot 3$ & & 41.0 & 28.6 & 30.4 & & 28.5 & 32.4 & 39.1 & \\
\hline Central-West & 40.6 & 34.8 & $24 \cdot 6$ & & $22 \cdot 1$ & 33.5 & $44 \cdot 4$ & & 33.9 & $32 \cdot 8$ & 33.3 & & 28.8 & $32 \cdot 9$ & $38 \cdot 3$ & \\
\hline
\end{tabular}


and South regions. Such results also reflect the differentiated conditions of food intake according to the different economic and social scenarios of the country, since the economically more developed regions (South, Southeast and Central-West) presented high levels of fat intake, especially saturated fats, according to the 2008-2009 Household Budget Survey ${ }^{(39)}$.

The high intake of meat is a concern of health agencies and entities, such as the Brazilian Society of Cardiology, in developing the first guideline on the consumption of fats and cardiovascular health ${ }^{(40)}$. However, there has been an increase in the consumption of meat with excess fat in Brazil, which, according to data from VIGITEL 2016 ${ }^{(41)}$, was $26.9 \%$ in 2015 and $32.0 \%$ in 2016, two times more frequent among men ${ }^{(40,42)}$, showing the need for action on food education.

Another intake behaviour pattern in the Brazilian adult population was the 'Alcohol and Smoking' one and both are responsible for millions of deaths each year ${ }^{(43)}$. The excessive consumption of alcoholic beverages is associated with other risk behaviours, especially smoking $^{(44,45)}$, as was identified in a systematic review conducted in the $\mathrm{UK}^{(46)}$. It is worth noting that the additive effects of those substances have harmful consequences on health and on society in general, especially in the economic sphere, since they have an impact on safety, the labour market and societal security ${ }^{(44,47,48)}$.

Excessive consumption of alcoholic beverages and tobacco use are risk behaviours that usually begin at an early age and last a lifetime ${ }^{(49)}$, especially among men and individuals with lower schooling level ${ }^{(45)}$. In Brazil, alcohol abuse is also more frequent among men and occasional smokers ${ }^{(30)}$ and smoking, in turn, is also associated with men and populations with lower levels of education $^{(50)}$. In the present study, greater adherence to the 'Alcohol and Smoking' pattern was observed among men and among individuals with lower schooling levels, in line with other studies ${ }^{(30,44,50)}$.

Similar to that observed in the present study with regard to the 'Sedentary behaviour and Sugar' pattern, in a study carried out in the city of Minneapolis (USA), Fuglestad et $a l^{(7)}$ verified that the pattern denominated 'Visualization and feeding related to television' was characterized by high intake of sugar and fat.

Excessive time in front of the television and its influence on food behaviour have been investigated in the adult population ${ }^{(51-53)}$. The high prevalence of sedentary behaviour $(28.9 \%)$ in the Brazilian population ${ }^{(54)}$ may favour the consumption of obesogenic foods, commonly linked to television advertisements, contributing to the replacement of fruit and vegetable consumption by unhealthy foods ${ }^{(51-53,55)}$.

The pattern named 'Sedentary behaviour and Sugar' presented greater adherence among the population of lower age groups and higher schooling. Higher consumption of sweet foods among adults with higher schooling levels was previously described in Brazil ${ }^{(56)}$ and adolescents also have greater consumption of foods with a high amount of solid fats and with added sugar ${ }^{(57)}$.

Modifying risk behaviours for NCD can reduce all-cause mortality rates ${ }^{(2,3)}$ and thus identifying patterns of such behaviours is important to assist in controlling this group of diseases. However, knowing the patterns is not enough; it is necessary to adopt preventive actions aimed at reducing risk behaviours through public health policies that consider behaviour patterns present in the population. According to the $\mathrm{WHO}$, for the effectiveness of policies aimed at the prevention of NCD, besides the issues related to legislation, mass education is critical, since behavioural changes are difficult to happen in the absence of environmental changes that reflect local characteristics and that respect the cultural component ${ }^{(2)}$.

Furthermore, the additional analysis in the current study showed that the behaviours do not seem to be modified in the presence of a chronic disease. Therefore, we should consider actions for the entire population, regardless of the diagnosis of some diseases.

Despite the innovative approach and representativeness of the evaluated population, the present study presents some limitations. Among them is the sedentary behaviour indicator evaluated, in which little active work (like remaining seated) and the time spent in front of other types of screen (computer monitor, tablet, smartphone) were not measured, considering that these behaviours can contribute to total sedentary time in adults. Another possible limitation was the measurement of physical activity or sport only in leisure time. However, this strategy was adopted by the study to prioritize personal choices, without considering involuntary or compulsory physical activities, such as those practised in routine work or in active transportation (walking from place to place). In addition, behaviour factors were defined based on a few questions about diet. Another limitation is related to the contextual variable regions of the country, which may be confounded by individual-level characteristics, age distribution and education. However, for public policies both levels of information is important.

One of the strengths of the present study is the use of a probabilistic sample of Brazilian adults, using an appropriate technique of statistical analysis to group risk factors, considering that most of the research carried out on this subject in the country is restricted to evaluating the occurrence of risk factors alone or only the co-occurrence of factors in populations limited to states or regions, being mostly studies in the South and Southeast regions.

\section{Conclusion}

The risk behaviour patterns for NCD reflected the socioeconomic and demographic differences found in Brazil. This analysis, based on data from a nationally 
representative health survey, allowed the identification of Brazilian behavioural diversity in relation to lifestyle, considering several risk factors for NCD, in a holistic approach and integrated understanding of these behaviours. Our results indicate that public policies in a continental country such as Brazil should be tailored to better reach the less developed areas in the North and Northeast of the country. Also, gender and generational differences as observed in other countries should also be considered.

\section{Acknowledgements}

Acknowledgements: The authors are grateful to the Ministry of Health of Brazil and the Secretary of Health Surveillance for supporting and financing the health survey (NHS 2013). Financial support: A.P.P.D. received a PhD grant awarded by the National Scientific and Technological Development Council (CNPq). CNPq had no role in the design, analysis or writing of this article. Conflict of interest: None. Authorship: A.P.P.D. wrote this study, reviewed the literature and performed the analysis. P.R.M.R. and A.P.M. proposed the study analysis, performed the revision of the analysis and reviewed the literature. M.G.F. and D.B.C. performed the revision of the analysis, participated in the study design, reviewed the literature and helped with the discussion. N.F.M. and R.S. performed the critical review of the manuscript and helped with the discussion section. All authors contributed to multiple revisions of the article. All authors read and approved the final manuscript. Ethics of buman subject participation: This study was conducted according to the guidelines laid down in the Declaration of Helsinki and all procedures involving human subjects were approved by the National Commission of Ethics for Research in Human Beings, of the Ministry of Health, under the opinion number 328,159. Written informed consent was obtained from all subjects.

\section{Supplementary material}

To view supplementary material for this article, please visit https://doi.org/10.1017/S136898001900034X

\section{References}

1. World Health Organization (2010) Global Status Report on Noncommunicable Diseases 2010. Geneva: WHO.

2. World Health Organization (2011) Global Status Report on Noncommunicable Diseases 2011. Geneva: WHO.

3. World Health Organization (2013) Global Action Plan for the Prevention and Control of Noncommunicable Diseases 2013-2020. Geneva: WHO.

4. Spring B, Moller AC \& Coons MJ (2012) Multiple health behaviors: overview and implications. J Public Health (Oxf) 34, Suppl. 1, i3-i10.
5. Luoto R, Pratala R \& Lutela A (1998) Impact of unhealthy behaviors on cardiovascular mortality in Finland, 19781993. Prev Med 27, 93-100.

6. Leech RM, McNaughton SA \& Timperio A (2014) The clustering of diet, physical activity and sedentary behavior in children and adolescents: a review. Int J Behav Nutr Phys Act 11, 4 .

7. Fuglestad PT, Jeffery RW \& Sherwood NE (2012) Lifestyle patterns associated with diet, physical activity, body mass index and amount of recent weight loss in a sample of successful weight losers. Int J Behav Nutr Phys Act 9, 79.

8. Robinson SM, Jameson KA, Syddall HE et al. (2013) Clustering of lifestyle risk factors and poor physical function in older adults: the Hertfordshire Cohort Study. J Am Geriatr Soc 61, 1684-1691.

9. Steele E, Claro R \& Monteiro C (2014) Behavioural patterns of protective and risk factors for non-communicable diseases in Brazil. Public Health Nutr 17, 369-375.

10. Ha S, Choi HR \& Lee YH (2017) Clustering of four major lifestyle risk factors among Korean adults with metabolic syndrome. PLoS One 12, e0174567.

11. Sena EMS, Muraro AP, Rodrigues PRM et al. (2017) Patrones de comportamiento de riesgo para enfermedades crónicas y factores associados entre adolescentes. Nutr Hosp $\mathbf{3 4}$, 925-933.

12. McAloney K, Graham H, Law C et al. (2013) A scoping review of statistical approaches to the analysis of multiple health-related behaviors. Prev Med 56, 365-371.

13. Lessa I, Araújo MJ, Magalhães L et al. (2004) Simultaneidade de fatores de risco cardiovascular modificáveis na população adulta de Salvador-BA, Brasil. Rev Panam Salud Publica 16, 131-137.

14. Muniz LC, Schneider BC, Silva ICM et al. (2012) Fatores de risco comportamentais acumulados para doenças cardiovasculares no sul do Brasil. Rev Saude Publica 46, 534-542.

15. Costa FF, Benedet J, Leal DB et al. (2013) Agregação de fatores de risco para doenças e agravos crônicos não transmissíveis em adultos de Florianópolis, SC. Rev Bras Epidemiol 16, 398-408.

16. D'Amico MM \& Souza RKT (2014) Simultaneidade de fatores de risco cardiovascular controláveis: estudo de base populacional. Rev Bras Cardiol 27, 318-326.

17. Loch MR, Bortoletto MSS, Souza RKT et al. (2015) Simultaneidade de comportamento de risco para a saúde e fatores associados em estudo de base populacional. Cad Saude Colet 23, 180-187.

18. Barros MBA, Lima MG, Medina LPB et al. (2016) Social inequalities in health behaviors among Brazilian adults: National Health Survey, 2013. Int J Equity Health 15, 148.

19. Azeredo CM, Levy RB, Peres MFT et al. (2016) Patterns of health-related behaviours among adolescents: a crosssectional study based on the National Survey of School Health Brazil 2012. BMJ Open 6, e011571.

20. Szwarcwald CL, Malta DC, Pereira CA et al. (2014) Pesquisa Nacional de Saúde no Brasil: concepção e metodologia de aplicação. Cien Saude Colet 19, 333-342.

21. Souza Júnior PRB, Freitas MPS, Antonaci GA et al. (2015) Sampling design for the National Health Survey, Brazil 2013. Epidemiol Serv Saude 24, 207-216.

22. Damacena GN, Szwarcwald CL, Malta DC et al. (2015) O processo de desenvolvimento da Pesquisa Nacional de Saúde no Brasil 2013. Epidemiol Serv Saude 24, 197-206.

23. Marôco J (2010) Análise estatísitca com o SPSS statistics, $6^{\text {a }}$ ed., pp. 469-528. Porto Alegre, RS: Artmed.

24. Kaiser H (1974). An index of factor simplicity. Psychometrika 39, 31-36.

25. Olinto MTA (2007) Padrões alimentares: análise de componentes principais. In Epidemiologia Nutricional, pp. 213- 
225 [G Kac, R Sichieri and DP Gigantes, organizers]. Rio de Janeiro, RJ: Fiocruz-Atheneu.

26. Hofstetter H, Dusseldorp E, Empelen PV et al. (2014) A primer on the use of cluster analysis or factor analysis to assess co-occurrence of risk behaviors. Prev Med 67, 141-146.

27. Sociedade Brasileira de Cardiologia (2016) $7^{a}$ Diretriz Brasileira de Hipertensão. Arq Bras Cardiol 107, Suppl. 3, $1-86$.

28. Instituto Brasileiro de Geografia e Estatística (2010) Pesquisa de Orçamentos Familiares 2008-2009: Antropometria e Estado Nutricional de Crianças, Adolescentes e Adultos do Brasil. Rio de Janeiro, RJ: IBGE.

29. Ikeda N, Inoue M, Iso H et al (2012) Adult mortality attributable to preventable risk factors for non-communicable diseases and injuries in Japan: a comparative risk assessment. PLoS Med 9, e1001160.

30. Garcia LP \& Freitas LRS (2015) Consumo abusivo de álcool no Brasil: resultados da Pesquisa Nacional de Saúde 2013. Epidemiol Serv Saude 24, 227-237.

31. Villiers AT, Copley A, McGee H et al. (2016) The relationship of tobacco and alcohol use with ageing selfperceptions in older people in Ireland. BMC Public Health 16, 627.

32. Camões M \& Lopes C (2007) Dietary intake and different types of physical activity: full-day energy expenditure, occupational and leisure-time. Public Health Nutr 11, 841-848.

33. Estaquio C, Pecollo ND, Latino PM et al. (2008). Socioeconomic differences in fruit and vegetable consumption among middle-aged French adults: adherence to the 5 a day recommendation. J Am Diet Assoc 108, 2021-2030.

34. Monsivais P, Aggarwal A \& Drewnowski A (2012) Are socioeconomic disparities in diet quality explained by diet cost? J Epidemiol Community Health 66, 530-535.

35. Mackeback J, Brage S, Forouhl NG et al. (2015) Does the importance of dietary costs for fruit and vegetable intake vary by socioeconomic position? Br J Nutr 114, 1464-1470.

36. Instituto de Pesquisa Econômica Aplicada (2017) Atlas da Violência 2017. Fórum Brasileiro de Segurança Pública. Rio de Janeiro, RJ: IPEA.

37. Instituto Brasileiro de Geografia e Estatística (2017) Diretoria de Pesquisas, Estatística da Produção Pecuária junho de 2017. Rio de Janeiro, RJ: IBGE.

38. Instituto Brasileiro de Geografia e Estatística (2016) Produção da Pecuária Municipal 2015. Vol. 43. Rio de Janeiro, RJ: IBGE.

39. Instituto Brasileiro de Geografia e Estatística (2011) Diretoria de Pesquisas, Coordenação de Trabalho e Rendimento. Pesquisa de Orçamentos Familiares 2008-2009. http://www.ibge.gov.br/home/xml/pof_2008_2009.shtm (accessed May 2017)

40. Santos RD, Gagliardi ACM, Xavier HT et al. (2013) Sociedade Brasileira de Cardiologia. I Diretriz sobre o consumo de gorduras e saúde cardiovascular. Arq Bras Cardiol 100, Suppl. 3, 1-40

41. Brasil, Ministério da Saúde, Agência Nacional de Saúde Suplementar (2017) Vigitel Brasil 2015 Saúde Suplementar: Vigilancia de Fatores de Risco e Proteção para Doenças
Crônicas por Inquérito Telefônico. Brasília, DF: Ministério da Saúde.

42. Brasil, Ministério da Saúde, Agência Nacional de Saúde Suplementar (2017) Vigitel Brasil 2016 Saúde Suplementar: Vigilância de Fatores de Risco e Proteção para Doenças Crônicas por Inquérito Telefônico. Brasilia, DF: Ministério da Saúde.

43. World Health Organization (2014) Global Status Report on Alcohol and Health. Geneva: WHO.

44. Brasil, Secretaria Nacional de Política sobre Drogas (2010) I Levantamento Nacional sobre o Uso de Álcool, Tabaco e Outras Drogas entre Universitário das 27 Capitais Brasileiras. Brasília, DF: SENAD.

45. Anand A \& Roy N (2016) Prevalence and determinants of co-use of alcohol and tobacco among mem in working age group (18-59 years) in India. Epidemiol Biostat Public Health 13, e116421.

46. Meader N, King K, Byrne TM et al. (2016) A systematic review on the clustering and cooccurrence of multiple risk behaviours. BMC Public Health 16, 657-665.

47. Instituto Nacional de Câncer, Organização Pan-Americana da Saúde (2011) Pesquisa Especial de Tabagismo - PETab: Relatório Brasil. Rio de Janeiro, RJ: INCA.

48. Organisation for Economic Co-operation and Development (2015) Tackling Harmful Alcohol Use: Economics and Public Health Policy. Paris: OECD Publishing.

49. Heron J, Macleod J, Munafo MR et al. (2012) Patterns of alcohol use in early adolescence predict problem use at age 16. Alcohol 47, 169-177.

50. Malta DC, Vieira ML, Szwarcwald CL et al. (2015) Tendência de fumantes na população brasileira segundo a Pesquisa Nacional de Amostra de Domicilios 2008 e a Pesquisa Nacional de Saúde 2013. Rev Bras Epidemiol 18, Suppl. 2, 45-56.

51. Cleland VJ, Schmidt MD, Dwyer T et al. (2008) Television viewing and abdominal obesity in young adults: is the association mediated by food and beverage consumption during viewing time or reduced leisure-time physical activity? Am J Clin Nutr 87, 1148-1155.

52. Boulos R, Vikre EK, Oppenheimer S et al. (2012) ObesiTV: how television is influencing the obesity epidemic. Physiol Behav 107, 146-153.

53. Heinonen I, Helajärvi H, Pahkala K et al. (2013) Sedentary behaviors and obesity in adults: the Cardiovascular Risk in Young Finns Study. BMJ Open 3, e002901.

54. Mielke GI, Hallal PC, Rodrigues GBA et al. (2015) Prática de atividade física e hábito de assistir à televisão entre adultos no Brasil: Pesquisa Nacional de Saúde 2013. Epidemiol Serv Saude 24, 277-286.

55. Rehm CD, Matte TD, Wye GV et al. (2008) Demographic and behavioral factors associated with daily sugarsweetened soda consumption in New York city adults. J Urban Health 85, 375-385.

56. Claro RM, Santos MAS, Oliveira TP et al. (2015) Consumo de alimentos não saudáveis relacionados a doenças crônicas não transmissíveis no Brasil: Pesquisa Nacional de Saúde, 2013. Epidemiol Serv Saude 24, 257-265.

57. Pereira RA, Duffey KJ, Sichieri R et al. (2014) Sources of excessive saturated fat, trans fat and sugar consumption in Brazil: an analysis of the first Brazilian nationwide individual dietary survey. Public Health Nutr 17, 113-121. 